tion Report, 1946). A valuable account of the principles and methods of malaria control has also been given by Dr. G. Macdonald, director of the Ross Institute, in his "Notes on Malaria and its Control for Planters and Miners" (April 1946), a pamphlet which discusses, in addition to the principles and methods of control, the malarial parasite itself, its main carriers in the British Empire, the types of land associated with malaria in Malaya and the factors which affect the incidence of malaria.

Another major menace of the Allied Forces in the East was bacillary dysentery. In the British Forces this was treated with sulphaguanidine, but the United States medical men preferred sulphadiazine, which was, they claimed, more effective. Sulphaguanidine, however, is less likely to affect the kidney, and British opinion, therefore, considered that it was preferable in tropical countries where much fluid is lost by sweating and where the sufferer is often dehydrated. Sir Alexander discusses the use of sulphaguanidine, and also the use of D.D.T. against the flies which spread the organisms which cause bacillary dysentery.

Serious also was amcbic dysentery, and much experience of its control and treatment was gained. Sir Alexander especially mentions the cases which resist treatment; and the view that they do so because secondary pyogenic organisms, which infect the intestinal walls already damaged by Entamoba histolytica, render these cases intractable. He quotes the work of W. H. Hargreaves (Lancet, ii, 68 ; 1942), which indicates that a preliminary treatment with penicillin and a sulphonamide drug would remove these secondary organisms, so that the attack upon $\boldsymbol{E}$.histolytica with specific drugs such as emetine bismuth iodide, chiniofon, etc., then produces good results. Sir Alexander outlines the treatment which should be given.

Epidemic typhus was not a serious risk in Burma. Mite-typhus (scrub-typhus) was one of the greatest problems encountered in that country. The control of this disease, which is caused by Rickettsia orientalis and is transmitted by the larvæ of the mite Trombidium akamushi and perhaps by other species of this genus (see Nature, 157, 236; 1946), was helped by attacks upon the mite with dimethyl phthalate. The remarkable story of the mass production of the vaccine against this disease has been told by Fulton, F., and Joyner, L. (Lancet, Dec. 8, 1945, p. 729, and Buckland, F. E., et al., ibid., Dec. 8, 1945, p. 734. See also the Lancet, Sept. 8, 1945, p. 308). So serious was the menace of the disease that the production of this vaccine was given the highest priority. Special laboratories were rapidly erected, cotton rats, in the lungs of which the Rickettsia develops abundantly, were flown from the United States by the R.A.F., and the devoted work of volunteers, who took very considerable risks of severe illness or death during their work (the accidental infection of four of these workers is described by Van den Ende, M., et al. (Lancet, July 6, 1946, p. 4)), produced enough of the vaccine to inoculate a considerable number of troops in Burma. The collapse of Japan and the withdrawal of Allied troops from the areas in which the disease was prevalent have made it unlikely that the results of this mass inoculation will now give useful information; but research on the vaccine has not ceased.

The rest of Sir Alexander's article is devoted to notes on typhoid fever, only a few outbreaks of which occurred, to warnings about the use of sul- phonamides in the tropics where excessive sweating increases the risk of damage by these drugs to the kidney, to penicillin and to laboratory methods of the diagnosis of smallpox and other diseases. There are interesting notes on the importance of preventing sea-sickness in troops about to cross rough seas. Research done by the Medical Research Council in co-operation with military medical men showed that the most useful remedy for it was $1 / 100$ grain of hyoscine given one hour before embarking and repeated every six hours. If the dose has to be continued over a long period, it must be reduced.

In his note on the work of psychiatrists, Sir Alexander says that the successful placing of men, selected by psychological tests, was one of the successes of the recent war. Important also were centres for physical development. A final note on administration points out that medical personnel in an Army Medical Service are under complete administrative control, so that a study of this Service and of the results obtained by it is especially interesting now that a State medical service is to be introduced in Great Britain.

G. LAPAGE

\section{THE IRISH PILCHARD FISHERY}

$T$ HE fishery for pilchards (Sardina pilchardus, Wal.) off the coasts of Cornwall has been famous for many centuries, and also the French, Spanish and Portuguese fisheries for sardines, which are the same species of fish. It is not generally known, however, that there has been also, at various periods, a flourishing Irish pilchard fishery. The appearance of a detailed historical account of the Irish pilchard fishery is therefore particularly welcome as being at once interesting and instructive*.

An Irish pilchard fishery existed so far back as 1591 and probably earlier; but its activities can be traced with some degree of accuracy only from about the year 1611. This is done comprehensively and in detail in the body of the paper, and is admirably summarized at the end.

The records show that the pilchard, when it frequents Irish waters, does so mainly along the coasts of Waterford, Cork and Kerry, although it is by no means confined to those counties. But the fishery has always exhibited extreme fluctuations, and, in recent times, the pilchard appears to have forsaken Irish waters almost entirely from 1904 until 1935. In the latter year shoals began to reappear, and in 1940 pilchards were plentiful once more off Ireland.

Unfortunately, there appears to be no demand in Ireland now for this fish, either fresh or preserved, and a vast potential source of food is not being exploited. But pilchards are occasionally caught when herring and mackerel are being fished, and even then they are usually thrown back into the sea. Nevertheless, the day yet may come when pilchards will command a ready market, even in Ireland, and this record of what the author calls "pilchard years" will then be invaluable. In the meantime, his paper is an outstanding contribution to our knowledge of this fishery over a very long period, and one hopes that its appearance will stimulate someone in a position to do so to prepare a similar historical account of the Cornish pilchard fishery.

G. A. Steven

* Proc. Roy. Irish Acad., 51, B, No. 5. Pp. 81-120. The Irish Pilchard Fishery. By Arthur E. J. Went. (Dublin: Hodges, Figgi and Co., Ltd.; London: Williams and Norgate, 1946.) 28. 6d. 